\title{
Format Rancangan Sistem Informasi Remaja Masjid (IRMA Masjid
}

\author{
Al-Istiqomah) \\ Annike Tri Wahyuni \\ Telkom University \\ Email: anniketriwahyuni@telkomuniversity.ac.id
}

\begin{abstract}
.Remaja masjid adalah perkumpulan pemuda masjid yang melakukan aktivitas sosial dan ibadah di lingkungan suatu masjid. Pembagian tugas dan wewenang dalam remaja masjid termasuk dalam golongan organisasi yang menggunakan konsep Islam dengan menerapkan asas musyawarah, mufakat, dan amal jama'i (gotong royong) dalam segenap aktivitasnya. Di Indonesia, organisasi pemuda remaja masjid seperti BKPRMI (Badan Komunikasi Pemuda remaja Masjid Indonesia, Tahun berdiri 1977), JPRMI (Jaringan Pemuda Remaja Masjid Indonesia, tahun berdiri 2003). Pada perancangan ini suatu sistem informasi berbasis web dengan system ini diharapkan mampu mengatasi berbagai kebutuhan dari user untuk mencari tahu acara-acara peringatan hari besar islam yang dikelola oleh remaja masjid.
\end{abstract}

Keywords: Web, Remaja Masjid, Sistem Informasi

Paper ini akan dipublikasikan di osf.io [a] menggunakan format standard perancangan sistem informasi [b]

\section{Introduction}

\subsection{Business case}

\subsubsection{Project Definition}

Remaja masjid adalah perkumpulan pemuda masjid yang melakukan aktivitas sosial dan ibadah di lingkungan suatu masjid. Pembagian tugas dan wewenang dalam remaja masjid termasuk dalam golongan organisasi yang menggunakan konsep Islam dengan menerapkan asas musyawarah, mufakat, dan amal jama'i dalam segenap aktivitasnya. Remaja masjid sebagai agen strategis dalam pemberdayaan umat perlu dibekali keilmuan dan ketrampilan yang di butuhkan,misalnya para aktivis remaja masjid juga perlu menekuni pengetahuan jurnalistik dan kewirausahaan. Hal itu penting untuk menguatkan dakwah dan pemberdayaan umat. Dua pengetahuan itu dapat menjadi sarana dakwah,maupun peningkatan SDM Remaja masjid sehingga mampu mandiri. Maka dengan adanya web ini dapat membantu remaja masjid dalam penyampaian agenda-agenda atau acara-acara yang akan dilaksanakan di masjid seperti peringatan hari-hari besar islam.

\subsubsection{Project Objective (SMART)}

a. Dapat mengetahui agenda-agenda yang akan dilaksanakan di masjid

b. Mempermudah dalam proses penyampaiannya seperti tanggal, waktu pelaksanaan, serta pengisi acara.

c. Mempermudah pemaantaukan IRMA terhadap masyarakat (jamaah) sekitar masjid

d. Meningkatkan mutu ibadah masyarakat (jamaah sekitar masjid

\subsubsection{System Definition}

Aplikasi IRMA Masjid Al-Istiqomah adalah aplikasi yang dapat membantu dalam penyampaian acara-acara atau agenda-agenda yang dilaksanakan oleh IRMA (Ikatan Remaja Masjid) yang dapat 
langsung diakses oleh masyarakat sekitar sehingga dapat mempermudah mengingatkan ataupun memberitahu perihal agenda-agenda yang akan dilaksanakan.

\subsection{System Requirement}

\subsubsection{System Function}

Web ini berisikan konten-konten terkait kegiatan remaja masjid maupun pengurus masjid seperti memberikan pemberitahuan akan diadakan acara yang berisikan tanggal, pukul, pengisi acara dan lain-lain. Hal ini dapat membantu remaja masjid agar tidak susah lagi menyampaikan pemberitahuan ini sehingga dapat mempermudah dan masyarakat sekitar juga dapat dengan mudah mengakses web ini.

\subsubsection{System Feature}

Fitur sistem dalam aplikasi berfungsi sebagai interface yang akan mempermudah proses penyampaian agenda atau acara yang akan dilaksanakan pada masjid atau peringatan hari-hari besar islam. Dari lingkup sistem informasi pada proses bisnis dapat dilakukan deskripsi fitur sistem sebagai berikut :

a. User (masyarakat) : melihat dan mengetahui agenda-agenda yang akan dilaksanakan

b. User (IRMA) : input agenda-agenda yang akan dilaksanakan

c. Admin aplikasi (IRMA atau pengurus masjid) : memiliki username dan password yang telah didaftarkan.

d. Interface aplikasi yang user-friendly

\subsubsection{Acceptance Criteria}

a. Terdapat admin khusus dalam menjalan aplikasi ini

b. Sistem infromasi dapat diakses oleh pengguna

c. Sistem informasi membantu IRMA (Ikatan Remaja Masjid) untuk melakukan semua kegiatan agenda masjid.

d. Semua data disimpan dalam basis data.

e. Semua data yang disubmit berdasarkan prosedur yang telah ada.

\subsubsection{System User Level}

Dalam hal ini sistem user level yang mendapatkan akses ke sistem informasi IRMA adalah admin (IRMA dan pengurus masjid) dengan login.

Click or tap here to enter text.

\section{Penjelasan SIngkat Terkait Metode}

Metode yang digunakan dalam penyusunan rancangan web ini adalah observasi dan waterfall. Dikarenakan era teknologi digital semua akses pemeberitahuan berbasis digital dengan adanya web ini dapat membantu masyarakat sekitar masjid dapat mengetahui agenda-agenda yang aka dilaksanakan oleh remaja masjid. Waterfall bertujuan untuk menghasilkan suatu sistem pada waktu yang telah ditentuakn dengan kualitas terbaik. Waterfall mengutamakan interaksi dengan stakeholder diawal project dikerjakan untuk mendapatkan gambaran yang jelas. Metode Waterfall merupakan salah satu metode yang sering digunakan oleh penganalisa sistem pada umumnya. Inti dari metode waterfall adalah pengerjaan dari suatu sistem dilakukan secara berurutan atau secara linear. Jadi jika langkah ke-1 belum dikerjakan, maka langkah ke-2 tidak dapat dikerjakan, jadi harus mengikuti tahapan demi tahapan untuk bisa lanjut pada langkah selanjutnya. 1. System information engineering and modeling Sistem informasi teknik dan pemodelan ini, pada sistem ini penulis mencari kebutuhan dari keseluruhan sistem yang akan diaplikasikan ke dalam software. 2. Requirements analysis Analisis kebutuhan, setelah mencari kebutuhan yang ada di sistem selanjutnya kebutuhan ini akan 
diintensifkan dan difokuskan pada pembuatan software dengan selanjutnya merancang interface. 3 . Design Setelah dirancang interface maka yang diperlukan yaitu atribut yang akan digunakan berupa struktur, arsitektur, algoritma, dan karakteristik yang dipakai untuk menjalankan sistem ini 4. Coding Pada tahapan ini design yang telah dirancang akan diubah kedalam bahasa pemrograman atau menerjemahkan data yang dirancang ke dalam bahasa pemrograman agar nantinya dapat dimengerti oleh mesin computer. 5. Testing Uji coba terhadap program yang dibuat, apabila error maka harus kembali ke tahapan coding untuk mencari kesalahan yang ada. 6. Maintenance Pemeliharaan, pada tahapan ini perubahan dan penambahan program dilakukan sesuai dengan permintaan.

Click or tap here to enter text.

\section{Proses Perhitungan}

\subsection{System Design}

Sistem ini dirancang untuk memenuhi kebutuhan masyarakat (Jamaah) masjid sekitar tentang agenda-agenda yang akan dilaksanakan di masjid oleh IRMA (Ikatan Remaja Masjid) dengan menggunakan Bahasa pemograman yang nantinya dapat diakses oleh jamaah.

Click or tap here to enter text.

\subsection{Data Flow Diagram (DFD)}

DFD adalah suatu diagram yang menggunakan notasi-notasi untuk menggambarkan arus dari data pada suatu sistem atau menjelaskan proses kerja suatu sistem, yang penggunaannya sangat membantu untuk memahami sistem secara logika, tersruktur dan jelas. Secara singkatnya, DFD adalah alat pemodelan untuk memodelkan alur kerja sistem.

DFD Level 0

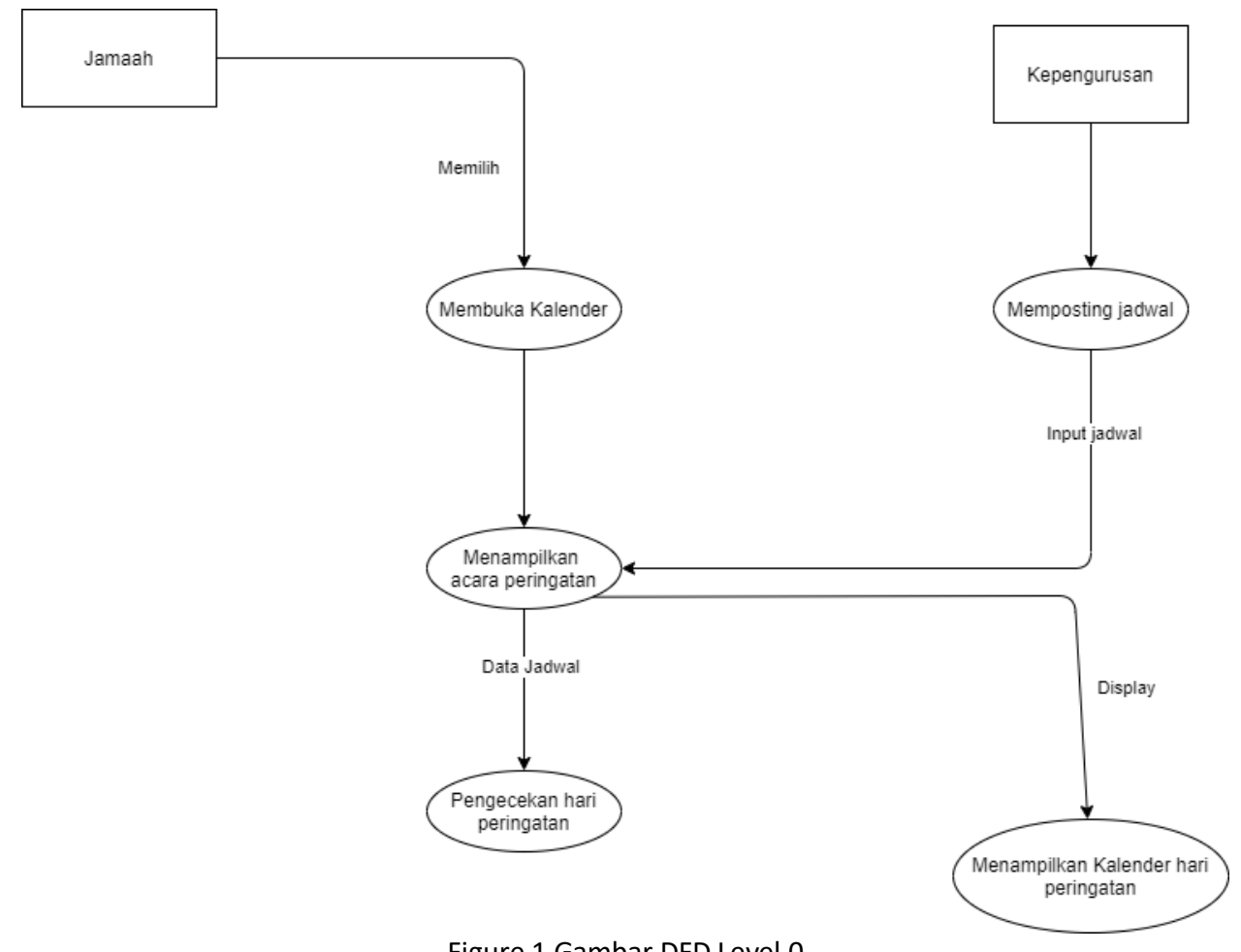

Figure 1 Gambar DFD Level 0 
DFD Level 1

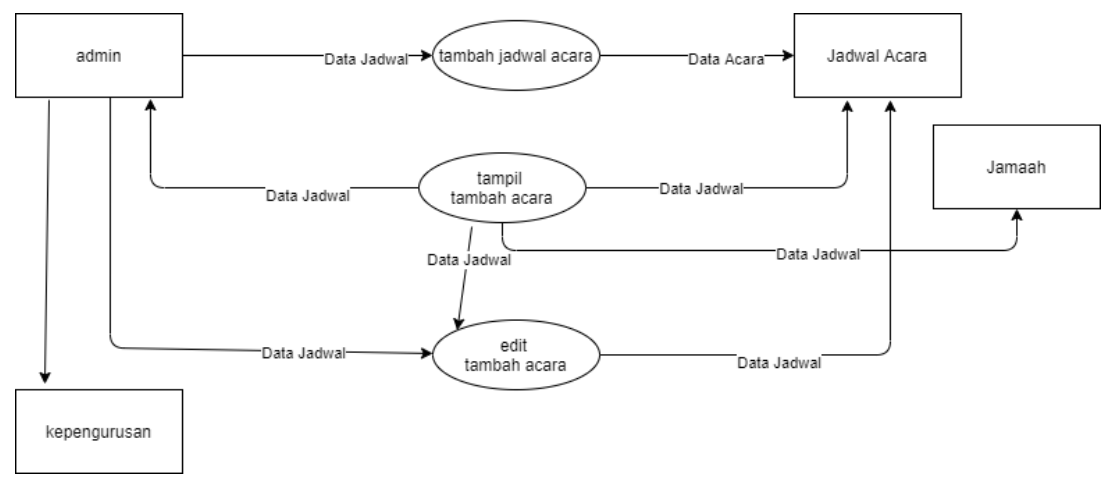

Figure 2 Gambar DFD Level 2

DFD Level 2

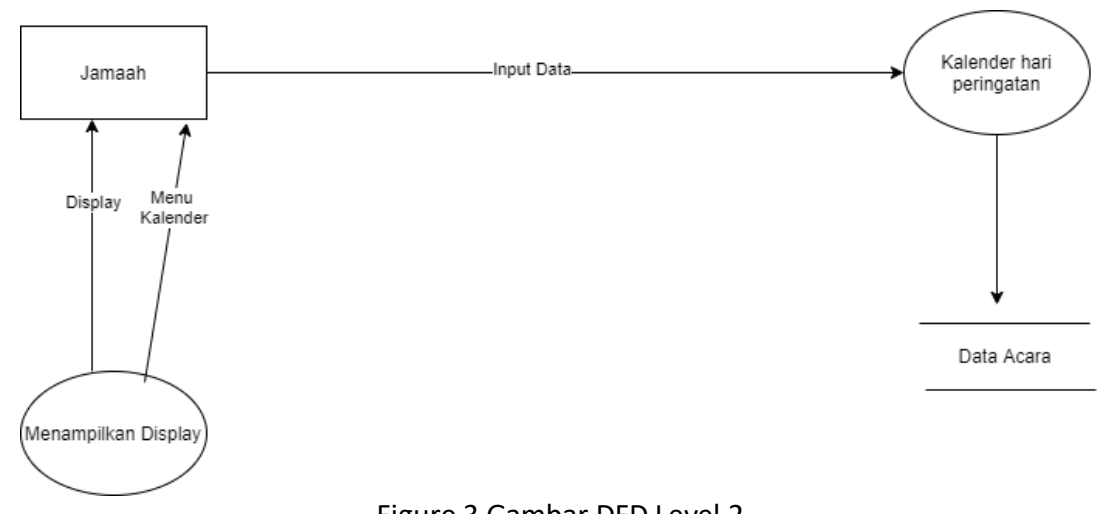

Figure 3 Gambar DFD Level 2

3.3. Entity Relationship Diagram (ERD)

ERD (Entity Relationship Diagram) adalah model konseptual yang mendeskripsikan hubungan penyimpanan (dalam DFD). Karena itu, ERD berbeda dengan DFD (DFD memodelkan fungsi system), atau dengan STD (State Transition Diagram), yaitu memodelkan system dari segi ketergantungan terhadap waktu. ERD digunakan untuk memodelkan struktur data dan hubungan dalam data, karena hal ini relative kompleks. (Pohan \& Bahri, 1997).

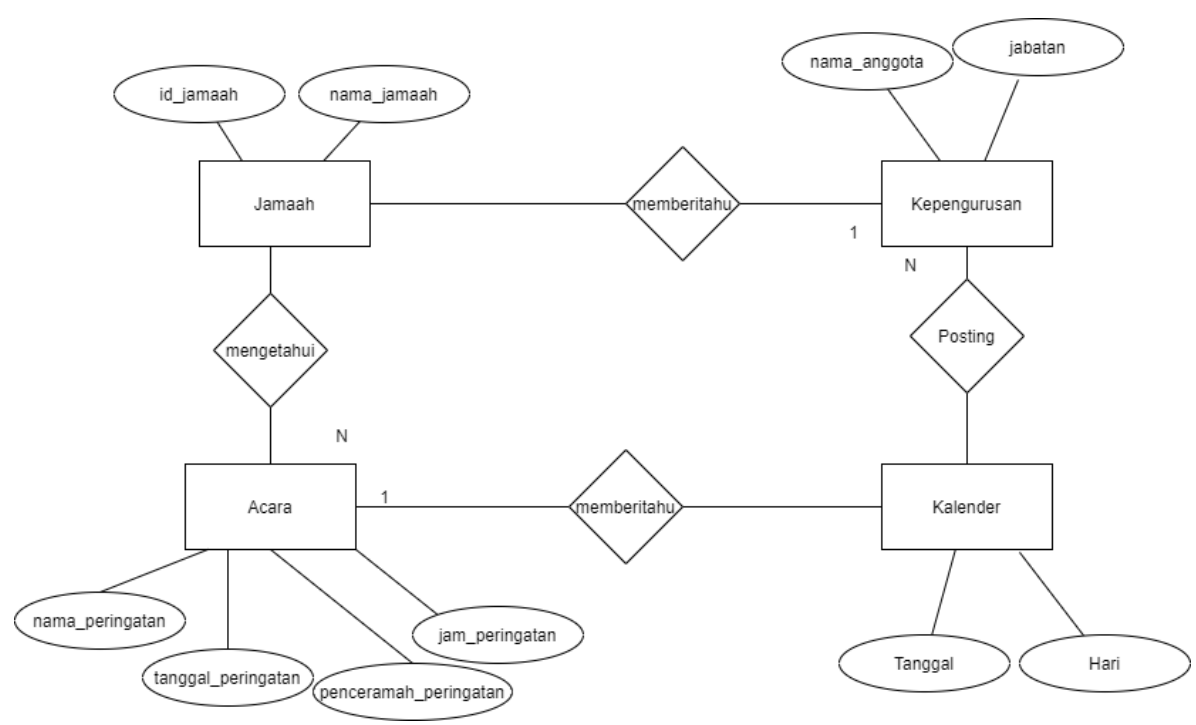

Figure 4 Gambar ERD 


\subsection{Database Design}

Database memiliki nama datauser dimana menampung user dalam himpunan dan rolenya masingmasing.

\subsection{Use Case Diagram}

Pada usecase diagram menunjukan superadmin berhak atas semua fungsi diantaranya fungsi login, manajemen berita/kegiatan.

Jamah masjid dapat mengakses web dengan masuk, pilih menubar yang ada sesuai dengan yang ingin diakses selanjutnya ditampilkan dan jamaah dapat mengaksesnya.

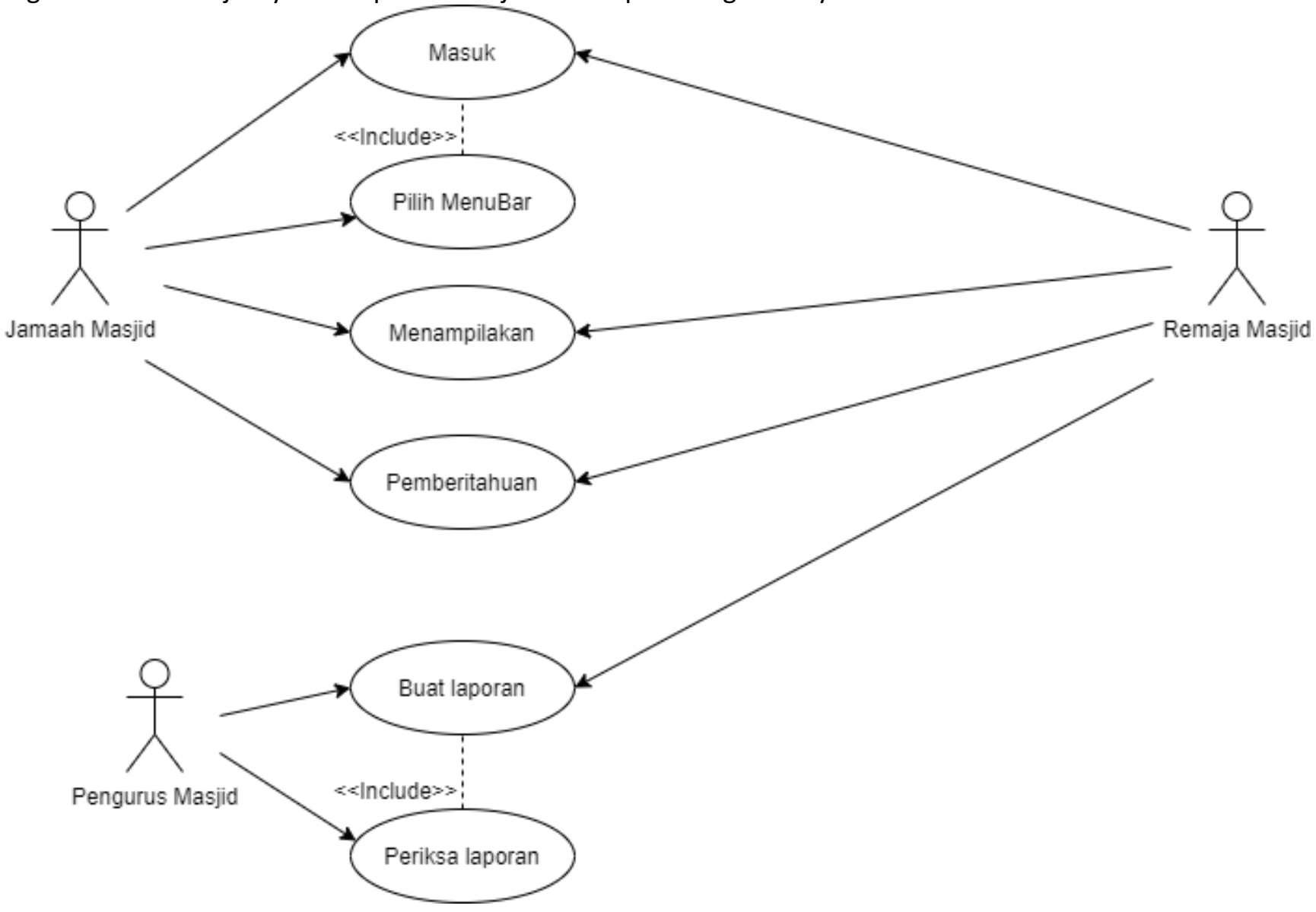

Figure 5 Gambar Use Case Diagram

\subsection{Activity Diagram}

Activity diagram merupakan diagram yang menggambarkan workflow (aliran kerja) atau aktivitas dari sebuah system atau proses bisnis. Diagram aktivitas menggambarkan aktivitas system bukan apa yang dilakukan actor. Dapat diliat pada activity diagram dibawah terdapat aktivitas pada saat login kemudian aktivitas sistem saat user memilih salah satu diantara tombol fungsi yang berada pada home. 
Activity Diagram

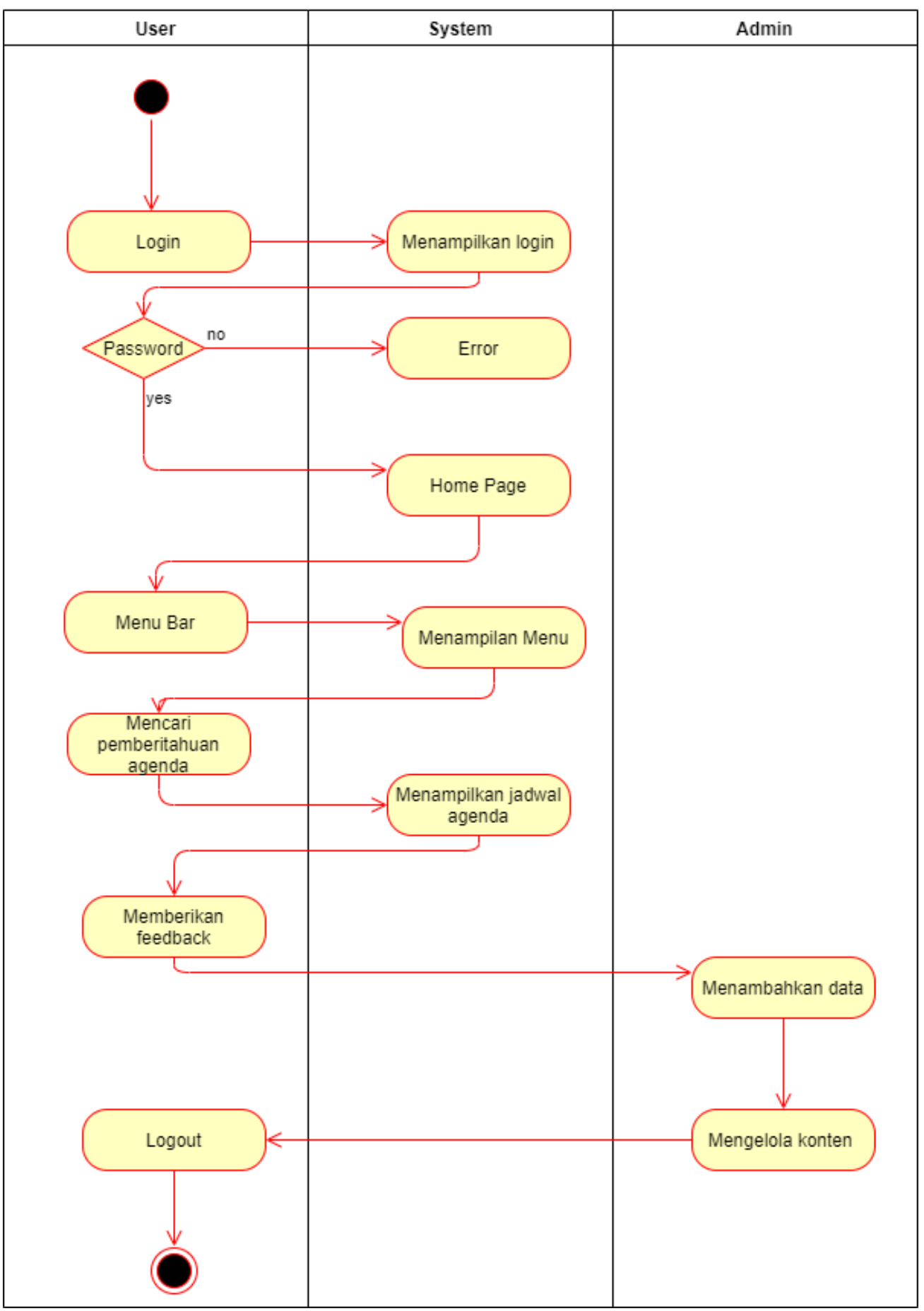

Figure 6 Gambar Activity Diagram

\subsection{Sequence Diagram}

Sequence Diagram adalah suatu diagram yang menggambarkan interaksi objek dan mengindikasikan (memberi petunjuk atau tanda) komunikasi diantara objek-objek tersebut. Sequence diagram digunakan untuk menggambarkan perilaku pada sebuah skenario dan mendeskripsikan bagaimana entitas dam sistem berinteraksi, termasuk pesan yang digunakan saat interaksi . 

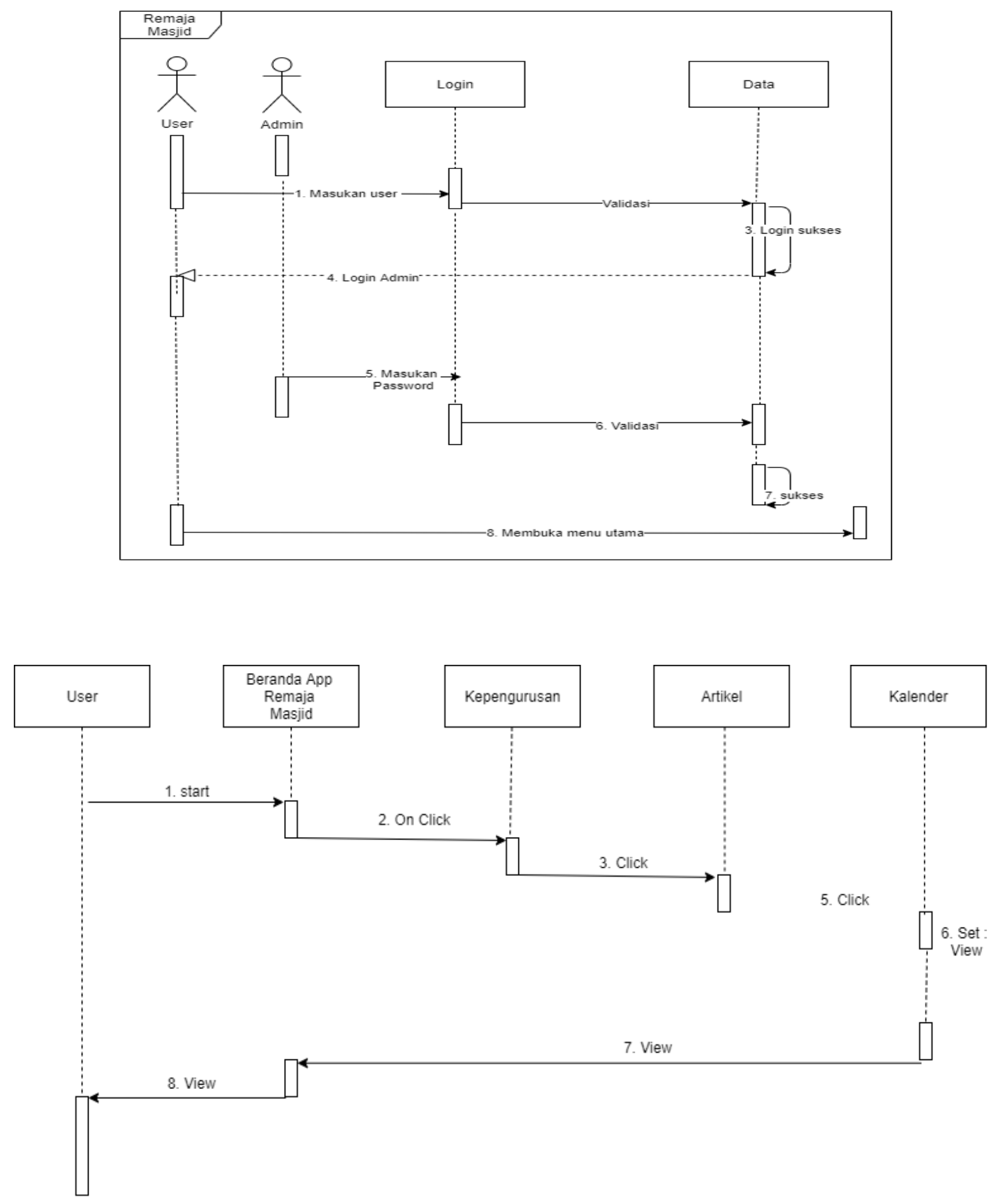

Figure 7 Gambar Sequence diagram login dan app

\subsection{Interface Design}

Click or tap here to enter text. 


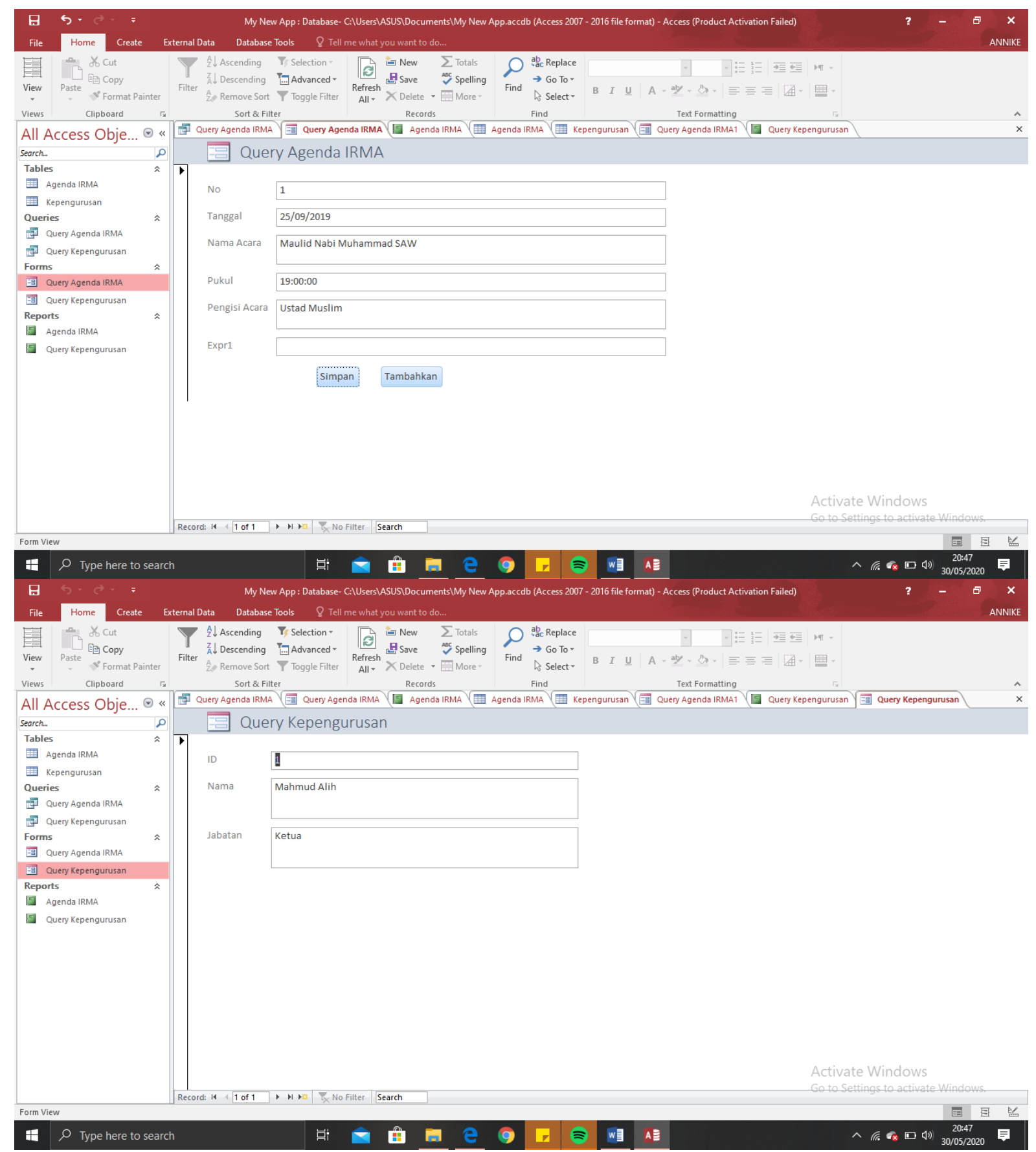




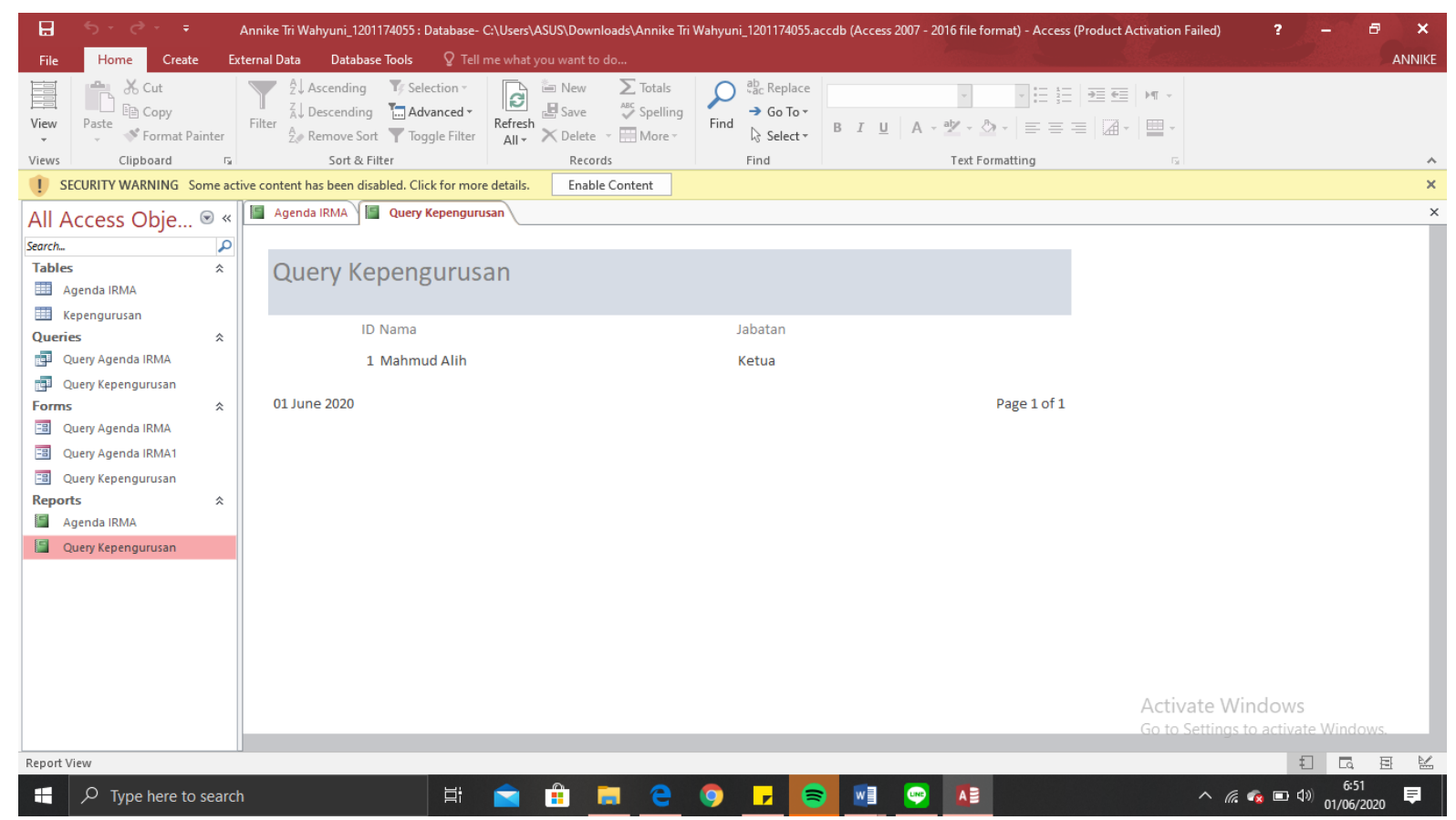

Figure 8 Gambar Interface Design

\subsection{Source Code}

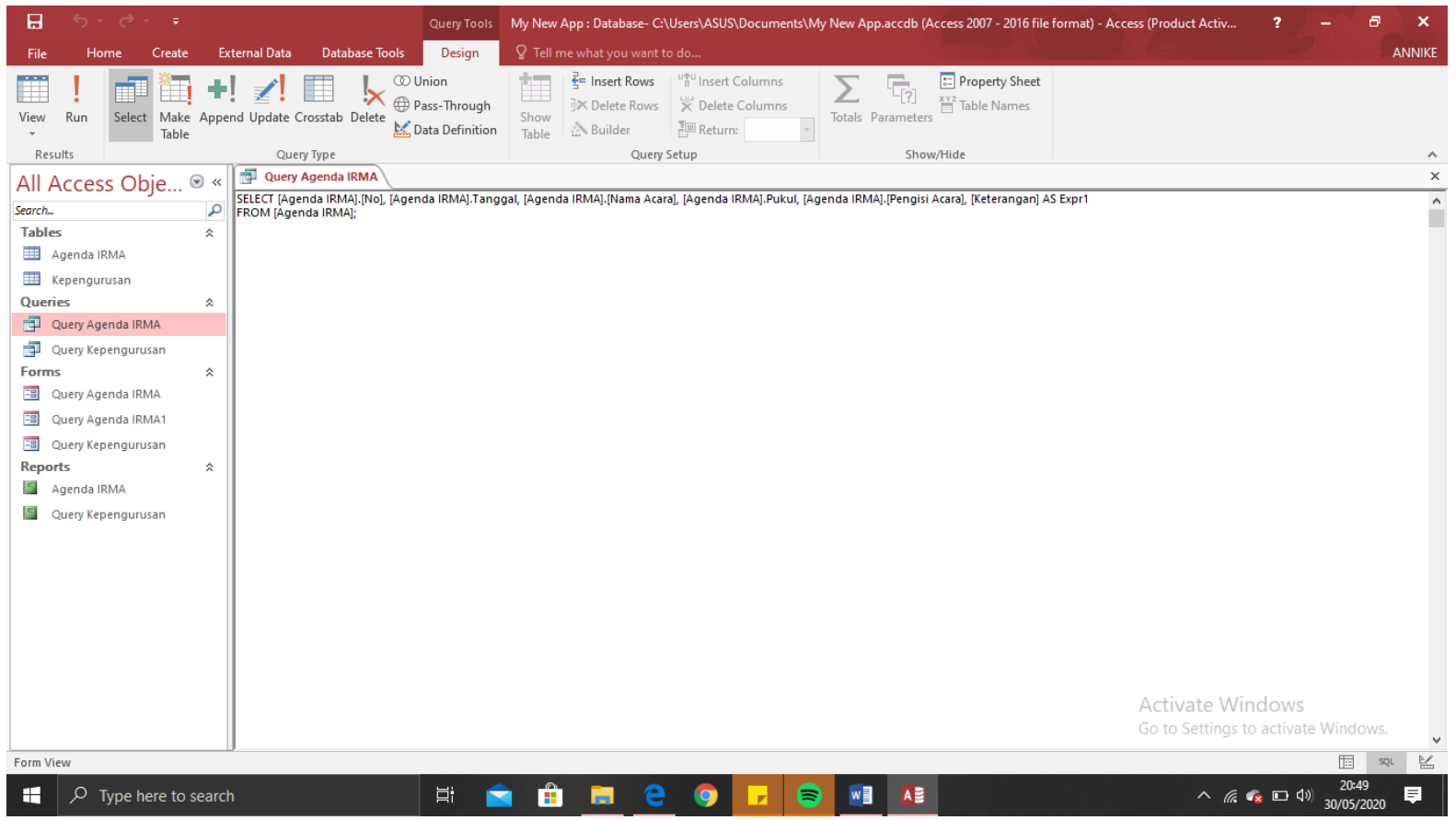




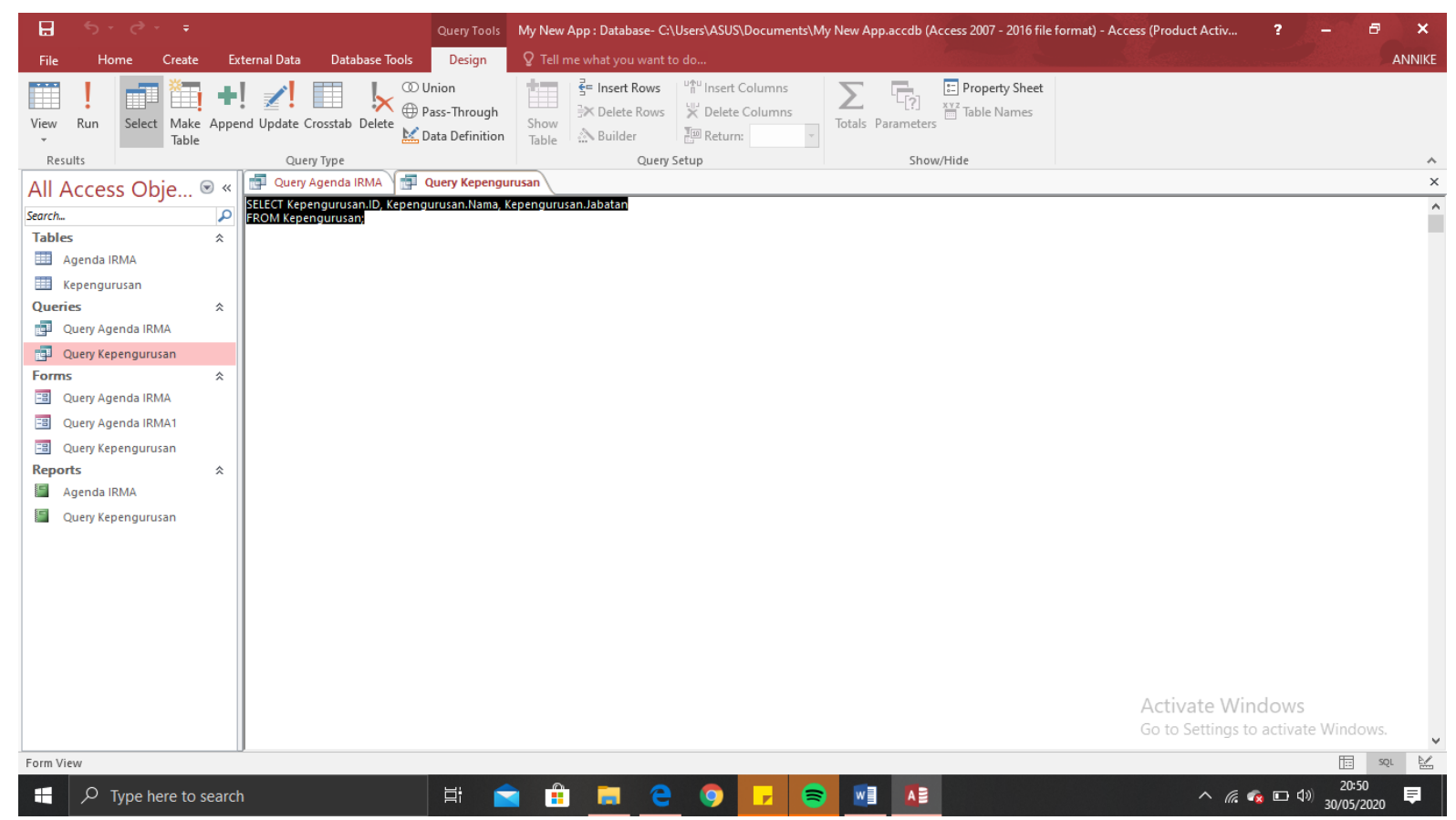

\section{Penutup}

4.1 Kesimpulan

Rancangan Aplikasi IRMA Masjid Al-Istiqomah dapat membantu jamaah (masyarakat) sekitar yang ingin mengetahui tentang agenda-agenda yang akan dilaksanakan di masjid. Dalam Aplikasi tersebut telah menyediakan fitur-fitur seperti beranda, kepengurusan irma, artikel tentang islam, kalender, dan pemberitahuan agar dapat mempermudah penyampaian tentang agenda-agenda di masjid.

\subsection{Saran}

Sebaiknya aplikasi ini ditambahkan lagi fitur-fitur pendukung yang dapat lebih bermanfaat seperti donasi online dan lain sebagainya..

\section{References}

[1] Wardana T.L., \& Aribowo, E. (2013). Perancangan Dan Implementasi Sistem Inforamsi Manajemen Kegiatan Masjid Studi Kasus: Masjid Jogokariyan Yogyakarta. Jurnal Sarjana Teknik Informatika, 1(1), 119-128.

[2] Rishamdani, J., Sofwan, A., Isnanto, R. R. (2008). Perancangan Website E-Commerce Penjualan Ikan Karang.

\section{Additional}

[a] R. Aurachman, "Review Terhadap OSF.IO Sebagai Sarana Publikasi Preprint," OSF Preprints, 17 May 2020. doi:10.31219/osf.io/rvumx , Available: https://osf.io rvumx

[b] R. Aurachman, "Kerangka Perancangan Sistem Informasi Sebagai Pembelajaran Mahasiswa Teknik Industri," osf.io, doi:10.31219/osf.io/tmpcn , 5 2020. Available: https://osf.io/tmpcn 